\title{
Thinking Maps Used as a Behavior Management Tool
}

\author{
Leah Harris ${ }^{1, *}$, Debra L. Cote ${ }^{1}$, Barbara Glaeser ${ }^{1}$, Melinda R. Pierson ${ }^{1}$, Shannon L. Sparks ${ }^{2}$ \\ ${ }^{1}$ Department of Special Education, California State University, Fullerton, 92831, California, United States \\ ${ }^{2}$ Department of Special Education, Rehabilitation \& Counseling, California State University, San Bernardino, 92407, California, \\ United States
}

Received October 5, 2020; Revised November 26, 2020; Accepted December 6, 2020

\section{Cite This Paper in the following Citation Styles}

(a): [1] Leah Harris, Debra L. Cote, Barbara Glaeser, Melinda R. Pierson, Shannon L. Sparks, "Thinking Maps Used as a Behavior Management Tool," Universal Journal of Educational Research, Vol. 8, No. 12B, pp. 8085-8091, 2020. DOI: 10.13189/ujer.2020.082610.

(b): Leah Harris, Debra L. Cote, Barbara Glaeser, Melinda R. Pierson, Shannon L. Sparks (2020). "Thinking Maps Used as a Behavior Management Tool." Universal Journal of Educational Research, 8(12B), 8085-8091. DOI: 10.13189/ujer.2020.082610.

Copyright $\mathrm{C} 2020$ by authors, all rights reserved. Authors agree that this article remains permanently open access under the terms of the Creative Commons Attribution License 4.0 International License

\begin{abstract}
Thinking Maps is an academic tool that allows students to organize information in a way that supports cognitive processes [1]. Thus far, research on Thinking Maps has been based on students' academic outcomes. Yet, Thinking Maps can provide students with academic as well as behavioral support while only using one tool to accomplish both. Teachers may feel overwhelmed and not adequately prepared to address the behavioral challenges inside or outside the classroom. Providing visual models can help all levels of learners (i.e., English Learners) in understanding how to use a Thinking Map that has been adapted for a behavior modification. Visual models can promote independence and minimal guidance when students are using Thinking Maps. More peer-reviewed research needs to be available and conducted on the general use of Thinking Maps for general and special education settings as well as across the grade levels of K-12. There also needs to be more research on the use of Thinking Maps for behavioral purposes across multiple grade levels and settings. Within this study, Thinking Maps was adapted for behavior modification and a handbook was developed. Participants were surveyed and provided feedback on ways to improve the handbook. Overall feedback suggested participants found the handbook beneficial for use with students in helping them to understand behavior.
\end{abstract}

Keywords Thinking Maps, Positive Behavior Supports, Behavior Management, Behavior Modification

\section{Thinking Maps Used as a Behavior Management Tool}

Now more than ever, school settings are diverse in nature. Everyday students bring an array of unique dynamics to the classroom (i.e., feelings, situations, experiences) [2]. Within this diverse element, many students, those in general and special education settings, need help with improving inappropriate behaviors [2]. Students in need of behavioral support may demonstrate inappropriate behaviors that disturb the learning taking place, for all in the classroom [3],[4]. When students demonstrate difficult behaviors, teachers may become stressed which can lead to burnout [5]. Positive teacher-student interactions can decline in quality if teachers feel stressed in the classroom.

Students, who qualify for special education services, must receive academic, behavioral, and other types of support to provide them with a "free and appropriate education" conducted in the "least restricted environment" [6]. When a student's behavior does not allow the student, or other classroom members to learn, the individualized education plan (IEP) team needs to reflect on the use of Positive Behavior Supports (PBS) for the student [6]. Both students in general and special education settings may need behavioral supports to help not only the individual student, but also the entire classroom.

Teachers must work to meet the diverse needs of all their learners in the classroom. Within diverse settings, teachers may come across situations where challenging behaviors are presented. Teachers may also encounter 
students who need more academic supports than other students.

In diverse classrooms, especially inclusive settings, teachers and other members of educational teams require ways to address multiple academic and behavioral challenges in the classroom [7].

Currently in elementary and secondary education, the transition from State Standards to Common Core State Standards is taking place. The Common Core State Standards are a way for states to come together and hold the same academic expectations for all students across all grade levels [8]. Students with disabilities are held to the Common Core State Standards however, they continue to have an IEP that specifies the accommodations and supports put into place for student learning [8]. The Common Core State Standards is designed to allow students to learn important skills such as the ability to solve problems and to be able to think critically [8].

Within the Common Core State Standards, students need to be given the opportunity to collaborate with peers as well as time to problem solves challenging concepts [9]. Some of these concepts that are included in the Common Core State Standards are known as $21^{\text {st }}$ Century Skills or Competencies [9]. $21^{\text {st }}$ Century Concepts are skills students need to have in order to be successful in a world that relies on both interpersonal and intrapersonal communication [9]. It is important that students have fundamental communication skills by the time they exit the public-school system [8].

The goal of the Common Core State Standards is to create better learning opportunities for students' future success [8]. Students who may not have yet developed or embraced the opportunity to use skills such as problem solving and peer-to-peer collaboration, can face academic difficulties and demonstrate behavioral challenges. Students who may not have strong self-management skills may have a difficult time regulating their emotions during academic lessons involving problem-solving activities related to their inability to complete classroom assignments. Students who have difficulties with self-regulation and peer relationships may not immediately benefit from collaboration with peers as these students may become frustrated with the level of social interaction required to engage with peers. Students who experience difficulties with these aspects of the Common Core State Standards will require some type of behavioral support that can guide them in regulating their emotions allowing them to create good habits in peer-to-peer communication techniques. The current curriculum changes in education call for academic and/or behavioral support for teachers to use during this crucial transitional phase from State Standards to Common Core State Standards. The supports used during this transitional phase can be used to assist teachers with continued implementation into the future. It would be beneficial for teachers to utilize a tool that helps students to think about what they are learning, allows for organization of learning new concepts, and can be used for self-regulation to change behavior. A tool such as this could be utilized in different settings, in different subjects, and could be applied to more than learning.

Thinking Maps may be able to fulfil the academic and behavioral requirements of a much needed classroom tool. Thinking Maps are visual tools that organize information for the learner, making it easier for the learner to process information in their long-term memory [1]. There are eight unique Thinking Maps (i.e., Bubble, Double Bubble, Tree, Flow, Multi-Flow, Brace, and Bridge) [1] developed to work with the eight cognitive processes that take place within the human brain during learning [10]. The following are the eight cognitive processes on which each individual Thinking Map is founded: (1) context, (2) qualities (3) comparing and contrasting, (4) categorizing, (5) part-whole, (6) sequencing, (7) cause-effect, and (8) analogies [10].

Teachers found that students failed to demonstrate difficulties when using Thinking Maps for academic purposes since they were able to visually view the thinking process [11]. Since Thinking Maps made it easier for students to use and visualize the thinking process, it was hypothesized that Thinking Maps would help students visualize their behaviors representing different cognitive processes, to analyze and ultimately change behavior. The purpose of this study was to create a handbook using Thinking Maps [1] adapted for behavior modification, to assist general and special education teachers who have students in their classrooms who exhibit repetitive inappropriate behaviors.

The following research question guided the study: (1) When provided with a Thinking Map adapted for behavior modification and teacher instruction on how to use, do teachers perceive elementary age students will be able to reflect on their behaviors? (2) When provided with a Thinking Map adapted for behavior modification and teacher instruction on how to use, do teachers perceive elementary age students will be able to understand their behaviors?

\section{Methods and Participants}

Participants in the study were general education teachers who served students in Transitional Kindergarten (TK) through grade six $\left(6^{\text {th }}\right)$. Fourteen of the participants were female teachers and one participant was a male teacher. Participants' teaching experience varied from 1-30 years (see Table 1). Participants held Mild/Moderate, Resource Specialist and Administrative Credentials. They were selected using convenience sampling [12]. Ethnicities of participants varied from Cambodian, Indian, Caucasian as well as Hispanic/Latino(a) as demonstrated in Figure 1. 
Table 1. Participant Grade Levels, Gender and Range of Years Teaching

\begin{tabular}{|c|c|c|c|}
\hline Grade Level & $\begin{array}{ll}\text { Number } & \text { of } \\
\text { Participants } & \\
\end{array}$ & Gender of Participants & Range of Years Teaching \\
\hline Transitional Kindergarten & 2 & Female & 6-10 (SDC Experience), 26-30 \\
\hline Second Grade & 2 & Female & $\begin{array}{l}0-5 \text { (10 Years After School Program } \\
\text { Instruction), } 11-15\end{array}$ \\
\hline Third Grade & 1 & Female & $16-20$ \\
\hline Fourth Grade & 2 & Female & $6-10,16-20$ \\
\hline Fifth Grade & 1 & Female & $16-20$ \\
\hline Resource Specialist (Elementary) & 2 & Female & $11-15,16-20$ \\
\hline SDC Early Childhood & 1 & Female & $11-15$ \\
\hline SDC Secondary & 1 & Male & 0-5 (SDC Elementary Prior) \\
\hline Early Childhood Gen Ed. & 1 & Female & 21-25 (Taught Kindergarten Prior) \\
\hline Instructional Coaching & 1 & Female & $16-20$ \\
\hline $\begin{array}{l}\text { Elementary RSP } \\
\text { Total number of participants }\end{array}$ & $\begin{array}{l}1 \\
15\end{array}$ & Female & 16-20 (Admin. and SDC Experience) \\
\hline
\end{tabular}

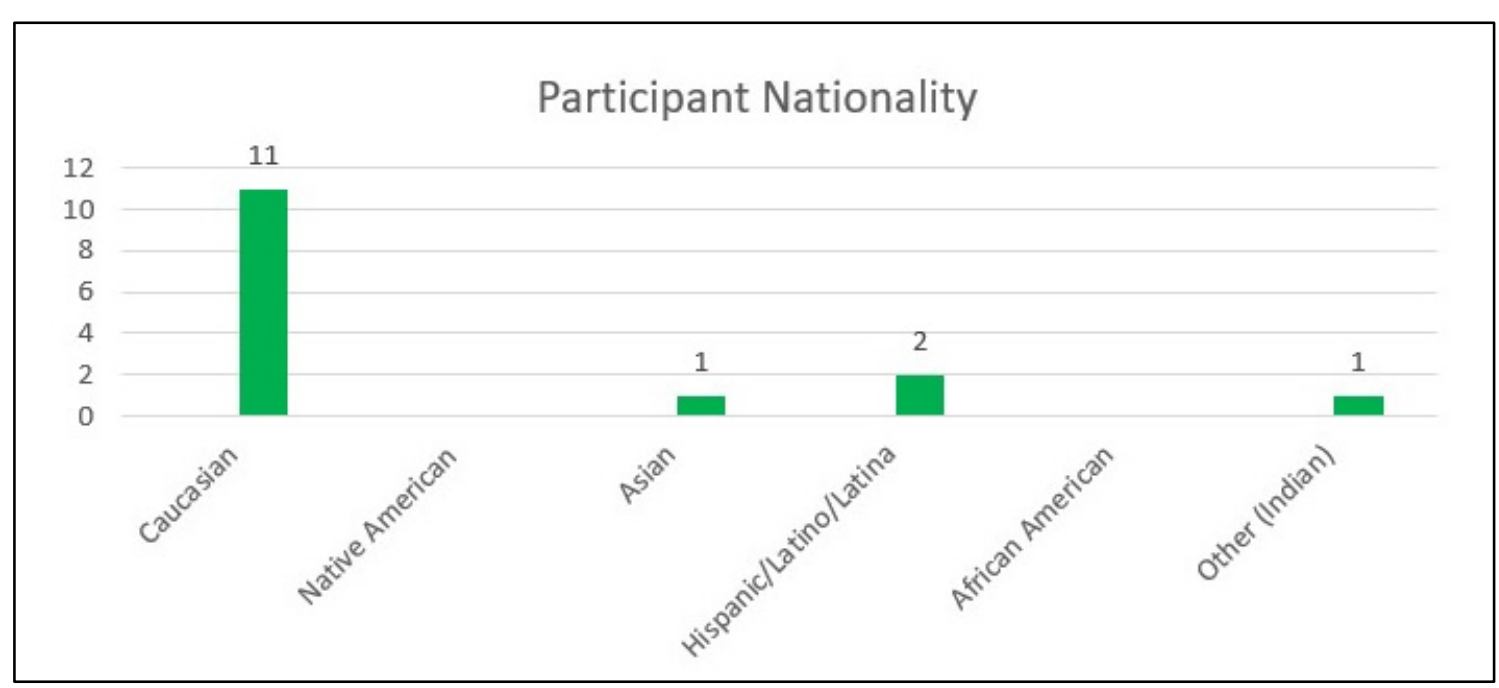

Figure 1. Participant Nationality

\section{Materials}

An adapted handbook was created for elementary school teachers to reference quickly and easily when a student demonstrated an inappropriate behavior. The handbook was designed to help teachers address repeated inappropriate behaviors in a proactive manner instead of reacting to students after the fact.

The handbook contained an explanation, for teachers, of when and how each adapted/modified Thinking Map for behavior modification, should be used. For instance, the handbook explained which adapted map would be appropriate based on a student's specific behavioral concern. Teachers were given the opportunity to choose how they wanted to approach the situation. For example, if a student has a repeated problem of taking the belongings of other students without asking, the teacher can choose which approach to take. The teacher could choose to have the student define what being a respectful classmate is, or map out what happened before and after the student took the other student's belongings. However, no matter which approach (i.e., thinking map) was chosen, the teacher still took the time to discuss what a better choice would be for the next time the student was in that particular situation. When using Thinking Maps adapted for behavior modification, teachers were encouraged to tell students to draw pictures or write words that correlate with the situation, based on the individual student's abilities.

Thinking Maps were created and adapted for behavioral situations, but the map remained the same [1]. However, instead of using Thinking Maps to support academic learning, the modified Thinking Maps were used to support the change of the desired behavior. The teacher participants used the same Thinking Maps they were trained on and used the same strategies, to guide student thinking, that they were initially taught.

\section{Thinking Maps}

Thinking Maps are used by elementary school teachers' district wide in the Orange Unified School District in 
California. Over $86 \%$ of participants receive formal district training on how to use Thinking Maps. When using Thinking Maps, the teacher (s) first needed to grasp what the students needed to do with the information. For example, do the students need to compare or contrast ideas, define something or describe something? Once the teacher decides what students need to do, the teacher then chooses the appropriate Thinking Map to utilize. With group lessons, the teacher prompts the students with questions to guide instruction [1]. When lessons include independence and students have learned how to use specific Thinking Maps, teachers can gauge how much guidance is necessary based on individual needs or the needs of the classroom. The following sections contain the different types of Thinking Maps, how they are traditionally used for academic purposes, and how they were used within the context of behavior in the adapted handbook.

\section{Circle Map}

A Circle Map is used for students to define a concept word or an idea, such as, words that start with the letter A [1]. Within this handbook an adapted Circle Map would be used when a student who needs clarification on an expected appropriate behavior. Students would also utilize an adapted Circle Map when thinking of appropriate behaviors that can replace inappropriate behaviors. An example of a Circle Map provided within the handbook was adapted for students who may exhibit difficulties in developing and maintaining friendships. Within the inner circle the following question was asked, "How can I be a good friend?" The outer layer of the circle focused on options/and or choices the student has or could have: (1) Use kind words, (2) Share, (3) Offer to help, (4) Invite my friends to play, and (5) Take turns. A Circle Map can be adapted and modified for any behavior the teacher wants the student(s) to problem solve.

\section{Bubble Map}

A Bubble Map helps individuals describe something using adjectives to accomplish the task [1]. A Bubble Map contains one large circle in the middle with the idea that is being described [1]. In the handbook, a Bubble Map was suggested to be used to help students describe how they felt after a social situation as well as how they felt about themselves and/or others.

\section{Double Bubble Map}

Double Bubble maps are used when students need to compare and contrast two ideas [1]. The circles that have extending lines connecting to both large circles are the items that both ideas have in common while the other small circles are the items of which are specific to the idea it is connected to [1]. A Double Bubble Map was adapted for behavior modification for use when students compared and contrasted what their actions were in a situation and appropriate expectations of the situation or setting of which the behavior occurred. The Thinking Map handbook used a Double Bubble Map for behavior modification. Within the first inner bubble the following question was asked, "What I did to get a turn on the swing." The outer bubbles showed the following responses: (1) Yelled at Vanessa, (2) Told Vanessa she is not my friend, and (3) Kicked sand at Vanessa when she was on the swing. The second inner bubble that compared and contrasted both ideas, "How we can nicely ask for a turn on the swing." The outer bubbles showed the following responses, (1) Ask for a turn using nice words, (2) Count to 20, then ask for a turn, and (3) Wait for someone to be finished on the swing. The Double Bubble Map allows for student(s) to compare and contrast the ultimate desired expectation and how they choose to respond the situation.

\section{Tree Map.}

A Tree Map is used for the task of organizing information into groups [1]. At the top of the Tree Map is the category or main idea of what is being classified [1]. A Tree Map was adapted for behavior modification to be used when students needed to identify where the replacement behavior could be used and examples of what those could be in the different settings. It was suggested that a Tree Map would be used to supplement a newly learned behavior. The Tree Map may help a student review where the replacement behavior or newly learned behavior should be used.

\section{Flow Map}

A versatile Flow Map can serve the purpose of retelling a story, naming the steps of a procedure as well as solving problems with multiple steps [1]. A Flow Map was adapted for behavior modification to be used when describing what happened in a social situation such as a conflict. Each part of the situation was described in a box. A new box was added as a replacement of what actions the student could do instead. The adapted handbook recommends what happened before the student made a poor choice or why the student made a poor choice to be discussed and centered in the first box. It was noted that this step may come after the entire scenario is mapped out onto the Flow Map. A Flow Map was also adapted for behavior modification for use with students who may benefit from having the procedures accessible to them as reminders. An example provided in the handbook focused on coming back from recess. Students who have difficulty focusing on an academic task (i.e., math) and often display poor choices during an academic task could 
benefit from a Flow Map. The following "Coming Back from Recess" Flow Map was used in the handbook: (1) Walk inside the classroom to my desk, (2) Take my math homework out, (3) Turn in my math homework, and (4) Take out my library book to read. Implementing the following Flow Map would help a student who struggles with following procedures and often engages in poor choices (i.e., off task, verbal outburst).

\section{Multi-Flow Map}

Multi-Flow Maps are used to illustrate multiple causes and effects for a single event [1]. A Multi-Flow Map was adapted for behavior modification for use when students needed to look at what happened prior to making a poor behavioral choice and what the outcome of these consequences were. If the student had multiple occurrences of the same behavior, all the causes and effects of what happened in each situation could be used to help the student understand the multiple causes and consequences of the demonstrated behavior. It was noted in the adapted handbook, for teachers to create another Multi-Flow Map with the student that contains replacement strategies to use next time the situation arises.

\section{Research Design and Procedures}

A survey design was used to collect quantitative and qualitative data from teachers regarding the handbook. The survey used was a descriptive design.

The investigator collaborated with an administrator (i.e., principal), who wanted to give teachers at the school site, a resource to help them carry out the school's Positive Behavior Support Plan. The investigator used information from articles as well as the Thinking Maps training manual to choose which Map would be most appropriate in multiple situations. Due to changes in staffing, the audience of the handbook changed from a single school to teachers at multiple school sites across grade levels.

The project included three phases. During Phase One, the investigator decided which Thinking Maps would be appropriate to include in the handbook. The investigator collaborated with a principal to ask for suggestions on how the chapters of the handbook should be laid out. Collaboration between the principal and investigator assessed if the proposed use for each Thinking Map would be appropriate for the school site.

During Phase Two, teachers were asked if they were interested in participating in the research. During this stage the handbook and survey were created. During Phase Three the handbook was e-mailed to 20 teacher participants. The investigator e-mailed a follow-up survey link to the teachers. Teachers were given a completion date for the online survey and were given a one-week courtesy reminder through e-mail, to complete the survey. To gather as many responses as possible, participants were given a three-day extension to complete the survey

Once participants were selected and agreed to participate, the handbook was sent to teachers as an attachment through e-mail as well as the link to an online survey. Teachers were given two weeks to look through the handbook and respond to the survey. A follow up e-mail was sent one-week prior to the survey due date. An extension of three-days was given for participants to complete the survey. The data were analyzed using a t-test for the significance of the correlation coefficient since participant feedback was being applied to the handbook.

\section{Results}

Results suggested the handbook was organized in a logical way; $60 \%$ of participants strongly agreed and $40 \%$ of participants agreed. Data suggest goals for each Thinking Map were easy to understand as $60 \%$ of participants strongly agreed and $40 \%$ of participants agreed. Also, $53 \%$ of participants strongly agreed while $47 \%$ of participants agreed the explanations of each individual Thinking Map was easy to understand. Even though $40 \%$ of participants strongly agreed and $53 \%$ of participants agreed, $7 \%$ of participants disagreed that Thinking Maps adapted for behavior modification, were used following with the same guidelines as Thinking Maps for academic purposes. Over 50 percent (i.e., 53\%) strongly agreed that elementary students can use Thinking Maps to understand their behavior while $40 \%$ of participants agreed and 7\% were unsure. However, participants believed the information presented on Thinking Maps adapted for behavior modification, was valuable as $47 \%$ strongly agreed while $53 \%$ agreed. Most participants strongly agreed (60\%) the handbook made it easy for teachers to implement and use Thinking Maps adapted for behavior modification, while $33 \%$ of participants agreed and 7\% were unsure. The majority of participants agreed that students would better reflect on their behaviors when using Thinking Maps adapted for behavior modification as $60 \%$ strongly agreed and 30\% agreed. The results of this question are displayed below in Figure 2. The results suggest participants perceived students would be able to reflect on their behaviors and choices when using Thinking Maps adapted for behavior modification (see Figure 2). 


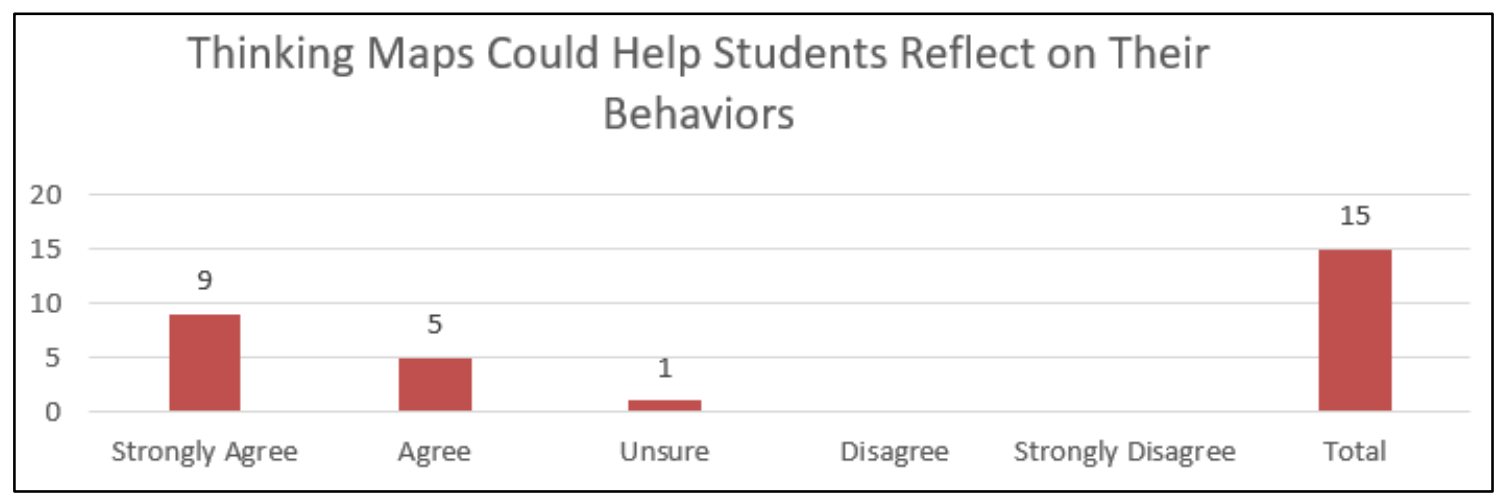

Figure 2. Thinking Maps Could Help Students Reflect on Their Behaviors

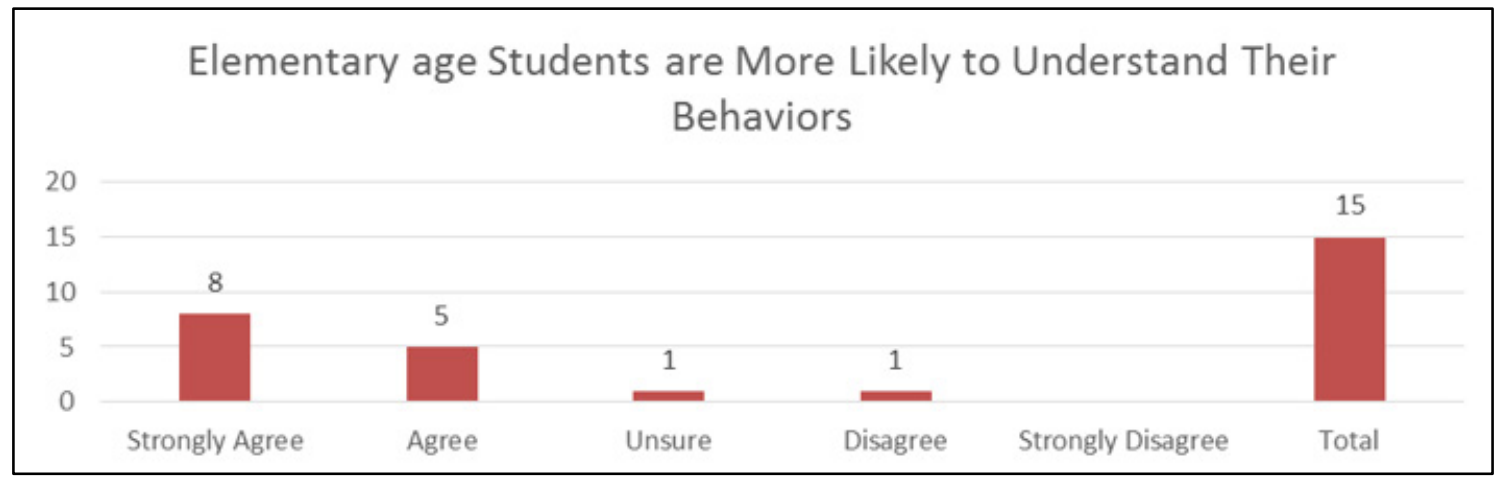

Figure 3. Thinking Maps Could Help Students Understand Their Behaviors

Eighty-six percent of participants felt that elementary students would be more likely to understand their behaviors after using Thinking Maps adapted for behavior modification, to understand their behavior. The data suggest teacher participants believed Thinking Maps adapted for behavior modification, would be a beneficial way to help students understand their behavior, think about the replacement behavior, and work to change inappropriate behaviors with the help of a teacher. These results are displayed in Figure 3.

Forty-seven percent of participants strongly agreed and $53 \%$ agreed, that students in elementary school settings were more likely to make better behavior choices when using the adapted handbook.

Participants were given the option to provide qualitative feedback in the form of comments at the end of the survey. Not all participants chose to include comments. One participant indicated she used the handbook and tried out the Bubble and Flow Maps with different students in the classroom. The participant also noted that it was easy to use with students on both occasions. Another participant expressed the handbook was a great idea and was easy to implement. Data indicated the handbook overall was well organized, easy to use and contained beneficial information regarding Thinking Maps adapted for behavior modification and how to use them. The positive feedback suggests that Thinking Maps adapted for behavior modification would be beneficial for teachers to use with students and could potentially reduce challenging student behaviors.

\section{Limitations}

We recommend future research with a larger population of participants using single subject or multiple baseline designs to assess the efficacy of the handbook with students. These designs may provide pre post data that would be generalizable. More male participants could be included in future research. Also, all grade levels (i.e., $\mathrm{K}-12$ ) should be represented in future studies. Different participants from varying districts may provide unique perspectives and information for the use of this handbook.

Participants were given two weeks to read the handbook and 10 days to complete the survey. A longer response time may have yielded different results. Researchers assessed teacher perceptions about the handbook and did not require participants to utilize the handbook in the classroom with students or within a school-wide setting.

\section{Directions for Future Research and Conclusion}

While a few of the participants were former 
administrators, it would be beneficial for those individuals to be asked about their perceptions of incorporating the handbook into a School-Wide Positive Behavior Support (SWPBS) plan. An administrator's willingness to utilize the handbook with staff and students within a SWPBS plan would also provide more in-depth information about its efficacy across grade levels/ages.

Participants made suggestions to incorporate visual models, graphics for students who do not write or are not ready to write as well as incorporating actual student examples. Researchers recommend a section of graphics for teachers to use with students who cannot write, thus offering supports that meet the diverse needs. Providing student examples can help teachers get a better understanding of how to use Thinking Maps adapted for behavior modification with their students. Another participant suggested providing examples for a variety of behaviors. One participant noted that the Frame of Reference was not used in the handbook nor in the examples in the handbook. A Frame of Reference is traditionally used with Thinking Maps to give students the opportunity to focus on where their information is coming from. The participant also noted that when students use the Frame of Reference with Thinking Maps adapted for behavior modification, they can describe how they learned the behavior. The participant also noted that using response frames would be beneficial for ELs to verbalize their understanding of the behaviors. Also, providing different behavioral examples may support teachers in having a better grasp of how Thinking Maps adapted for behavior modification can be used with diverse student populations. Lastly, data suggest the handbook would be valuable when encountering challenging behavioral situations in helping students to examine their behaviors.

\section{Discussion}

The researchers sought to improve the way teachers support diverse students with difficult behaviors by using a tool [1] adapted for academic and behavior modification purposes. Teachers need access to a resource that is already used in the classroom, to help students understand and reflect on their repetitive inappropriate behaviors. Researchers created a handbook using Thinking Maps adapted for behavior modification, to assist general and special education teachers and inform best practice. The findings provide insight into teacher perceptions of the adapted handbook and its use within a SWPBS plan.

\section{REFERENCES}

[1] Hyerle, D. \& Yeager, C., "Thinking maps: A language for learning." Cary, NC: Thinking Maps, Inc, 2007.

[2] Scott, T. M., Park, K. L., Swain-Bradway, J., \& Landers, E., "Positive behavior support in the classroom: Facilitating behaviorally inclusive learning environments.” International Journal of Behavioral Consultation and Therapy, Vol. 3, No.2, pp. 223-235, 2007. DOI: 10.1037/h010080

[3] Anderson, C. M. \& Spaulding, S. A., "Using positive behavior support to design to effective classrooms. "Beyond Behavior, Vol. 16, No. 2, pp. 27-31, 2007.

[4] Martens, K., \& Andreen, K., "School counselors' involvement with a school-wide positive behavior support intervention: Addressing student behavior issues in a proactive and positive manner." Professional School Counseling, Vol. 16, No. 5, pp. 313-322, 2018. DOI: $10.1177 / 2156759 X 1201600504$

[5] Gebbie, D. H., Ceglowski, D., Taylor, L. K., \& Miels, J., "The role of teacher efficacy in strengthening classroom support for preschool children with disabilities who exhibit challenging behaviors." Early Childhood Education Journal, Vol. 40, No. (1), pp. 35-46, 2012. DOI: 10.1007/s10643-011-0486-5

[6] Individuals with Disabilities Education Improvement Act of 2004, 42U.S.C. $\$$ P.L.108-446, $108^{\text {th }}$ Congress. https://sites.ed.gov/idea/?src=policy-page (accessed on Monday, September 28, 2020)

[7] Morrissey, K. L., Bohanon, H., \& Fenning, P., "Teaching and acknowledging expected behaviors in an urban high school," Teaching Exceptional Children Vol. 42, No. 5, pp. 26-35, 2010. DOI: 10.1177/004005991004200503

[8] Common Core State Standards Initiative, "About the standards." http://www.corestandards.org/about-the-standar ds/ (accessed: Thursday, October 1, 2020)

[9] Digital Chalkboard, " $21^{\text {st }}$ Century Skills." https://www.mydigitalchalkboard.org/portal/default/Conten t/Viewer/Content?action $=2 \&$ scId $=306588 \&$ sciId $=17934$, 2018. (Accessed on Friday, June 11, 2020)

[10] Hyerle, D. \& Williams, K., "Bifocal Assessment in the Cognitive Age: Thinking Maps for assessing content learning and cognitive processes." https://www.thinkingfou ndation.org/whole-school-change(accessed on Sunday, September 27, 2020).

[11] Kessler, C., Zuercher, D.K., \& Wong, C.S., "Thinking Maps: Research-based instructional strategy in a PDS. School-University Partnerships," Vol. 6, No.1, pp. 33-46, 2013.

[12] Cozby, P. C., “Methods of behavioral research.” New York, NY: McGraw Hill, 2009. 